\title{
Overlooked impacts of climate change on groundwater
}

\author{
Helen Rutter ${ }^{1 *}$ and Andrew Dark ${ }^{2}$ \\ ${ }^{1}$ Water and Land, Aqualinc Research Ltd, New Zealand \\ ${ }^{2}$ Research and Development, Aqualinc Research Ltd, New Zealand
}

*Corresponding author: Helen Rutter, Aqualinc Research Ltd, Bishopdale, Christchurch, New Zealand.

Received Date: May 08, 2020

Published Date: May 29, 2020

\section{Opinion}

Climate change is a current area of huge concern. City, district and regional councils are grappling with climate change implications for their respective areas and what advice they should provide to stakeholders about housing, infrastructure and land use into the future. There are many specific issues, including impacts of extreme events, long-term changes in rainfall or weather patterns that might affect the ability to grow crops, and coastal inundation from sea level rise. However, there are also some more subtle, but still important, aspects of climate change that are often overlooked, for example:

- $\quad$ Changing drinking water source reliability, for example due to increased flood flows in rivers and increased sediment loading, restricting the ability to take water, or decreased recharge to aquifers resulting in lower groundwater levels and less available allocation. In deep groundwater, effects of reduced recharge may not be seen for many years: and in contrast, the response to increased recharge may be prolonged, making planning for climate change effects difficult.

- Impacts from shallow groundwater in urban areas, including increased inundation of infrastructure, contribution to surface water flooding, and increased liquefaction risk. Shallow groundwater levels usually respond rapidly to rainfall events, and may cause surface inundation and/or reduce infiltration capacity in response to rainfall. Shallow groundwater in coastal areas, in addition, will be impacted by rising sea levels, further reducing the available "headroom". Horizontal infrastructure will be negatively impacted, with the potential for increased infiltration into waste water pipe systems, and derogation of infrastructure in areas where groundwater levels are impacted by tidal effects and intrusion of saline water. Shallow groundwater also impacts on the ability to carry out excavation work (see Figure 1), and may even have an impact on types of vegetation to plant.

- Impacts of shallow groundwater or SLR on land treatment of effluent and land drainage. In many areas of the world, application of treated effluent to the land is a necessary part of effluent treatment, but relies on there being sufficient unsaturated thickness to work. Control of shallow groundwater levels is sometimes facilitated by land drainage. In coastal areas, again shallow groundwater will respond to rainfall and sea level rise, and the combination of both increased extreme events and general SLR-induced groundwater levels may result in systems being unworkable (Figure 1).

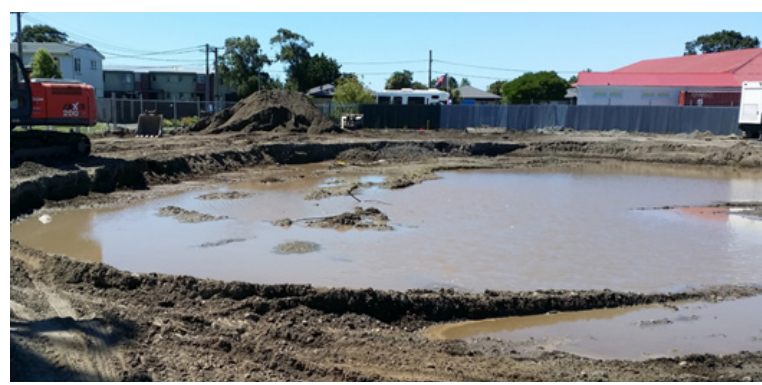

Figure 1: Shallow groundwater in an excavation for a retention basin in Christchurch.

Groundwater is often out-of-sight, out-of-mind, but consideration of these less obvious impacts of climate change 
is essential in order to be fully prepared for the future. In New Zealand, there are questions being asked including ones around land development decisions, controlling shallow groundwater infiltration into services to minimise volumes arriving at treatment centres, life-expectancy of existing infrastructure, and questions around sustainability of water supply sources.

However, groundwater is a 4-dimensional problem: it varies in space, with depth, and with time. It can't be dammed, and stop banks can't keep it out. It is on continuity with surface water, with flows going either way, depending on relative levels.

Currently, in New Zealand, central and local government are addressing many of the obvious climate change impacts. However, attention to the "overlooked impacts" is less coordinated. Individual councils, sometimes through research projects, but more often through their own funding, have identified specific issues within their own areas, and are investigating them at varying levels of detail.

In order to be able to understand, and predict, how groundwater levels will respond to future climate change, we need to be designing appropriate monitoring now, aiming to be able to understand the current scenario, and model future impacts. Unless we are proactive about this, there will be a huge lost opportunity cost, and we will be counting this for many years to come.

\section{Acknowledgment}

None.

\section{Conflict of Interest}

No conflict of interest. 